55 Robins LN. Epidemiology: reflections on testing the validity of psychiatric interviews. Arch Gen Psychiatry 1985; 42: 918-24.

56 Schaffer D. Attention deficit hyperactivity disorder in adults. Am J Psychiatry 1994; 151: 633-8.

57 Wolkind S, Coleman EZ. Adult psychiatric disorder and childhood experiences: the validity of retrospective data. Br J Psychiatry 1983; 143 188-91.
58 Yarrow MR, Campbell JD, Burton RV. Recollections of childhood. Monogr SoC Res Child Dev 1970; 35: 1-83.

59 Henry B, Moffitt TE, Caspi A, Langley J, Silva PA. On the 'remembrance of things past'. Psychol Assess 1994; 6: 92-101.

60 Holmshaw J, Simonoff E. Retrospective recall of childhood psychopathology. Int J Methods Psychiatric Res 1996; 6: 79-88.

\section{Psychiatrists in 19th-century fiction}

\title{
Hard Cash (1863), Charles Reade
}

\section{Fiona Subotsky}

Hard Cash is a polemical novel about the injustice and poor treatment of the insane and allegedly insane. While it made the author, Charles Reade (1814-1884), quite wealthy, Dickens, as the overall series editor, disclaimed responsibility for its opinions, which he presumably thought were too forcibly expressed. Reade had legal, and perhaps some medical, training. He did copious research, and points out in his preface that: 'I have accumulated during the last few years a large collection of letters from persons deranged in various degrees, and studied them minutely, more minutely than most Psychologicals study anything but Pounds, Shillings, and Verbiage.' The plot is complex, and the hero Alfred is forced into several different asylums, with contrasting regimes and doctors. I shall concentrate here on Dr Wycherley, assumed for reasons which will become evident to be at least in part a portrait of Dr John Conolly.

\section{Assessment}

Alfred Hardie, the lovelorn hero, has accused his father of misappropriating $£ 14000$, thus driving his intended future father-in-law to penury and madness. As he appears pale and miserable to his sister, the family doctor is called in; he diagnoses 'hyperaesthetic character' and then brings along a specialist, Dr wycherley. The latter is described as 'so saturated . . . with circumlocution, that ... he talked like an Article.' Indeed, before even seeing the young man the 'psycho-cerebral' announces that: 'from the diagnostics, I have no doubt whatever he is labouring under the first fore-shadowings of cerebro-psychical perturbation. To speak plainly, the symptoms are characteristic of the initiatory stage of the germination of a morbid state of the phenomena of intelligence.

Pressed to be more specific, Dr Wycherley warns that 'it is the premonitory stage of the precursory condition of an organic affection of the brain,' although at this stage eminently curable. He outlines the characteristic symptoms of the 'Incubation of Insanity': first 'Kephalalgia' or headache; second a 'morbid affection of sleep'; third, low spirits, often with a 'latent delusion', carefully concealed. Excitability is also frequent. Alfred's caring sister thinks her brother displays all these symptoms, and though her father is more sceptical, he begins to spot an advantage to himself.

Wycherley sums up thus, in a clearly self-serving manner: 'The most advisable course is to give him the benefit of the personal superintendence of some skilful physician possessed of means and appliances of every sort for soothing and restraining the specific malady.'

He departs with the following peroration:

'it is not logical, reasoning a priori, to assume the possibility that the studious or other mental habits of a Kephalalgic, and gifted youth, can be reversed, and erotic monomania germinate, with all the morbid phenomena of isolation, dejection of the spirits, and abnormal exaltation of the powers of wit and ratiocination, without some considerable impairment, derangement, disturbance, or modification, of the psychical, motorial, and sensorial functions of the great cerebral ganglion. But it would be equally absurd to presuppose that these several functions can be disarranged for months, without more or less disorganisation of the medullary, or even of the cineritious, matter of the encephalon. Therefore - dissection of your talented son would doubtless reveal at this moment either steatonatous or atheromatous deposits in the cerebral blood-vessels, or an encysted abscess, probably of no very recent origin, or, at the least, considerable inspissation, and opacity, of the membranes of the encephalon, or more or less pulpy disorganisation of one or other of the hemispheres of the brain: good morning!!'

Subsequently Dr wycherley and a compliant apothecary see Alfred and quiz him about his belief that his father has misappropriated money. Calling this a delusion, and his reaction 'excitement', they find grounds for his compulsory confinement to a lunatic asylum, which he is tricked into entering.

As to Conolly, his lectures were said by his son-in-law Henry Maudsley, in an intermittently unkind obituary, to have been 'diffuse and theoretical', 'vague and discursive', but to us both Reade and Maudsley seem at least as polysyllabic.

\section{Moral treatment}

Conolly is famous for popularising 'non-restraint' methods of caring for the mad - a system Alfred finds in place at the second asylum he is admitted to, run by Dr Wycherley. He is allowed to bathe and is examined by the assistant physician. His lesions from previous brutal treatment are noted, but no enquiries are made into his mind - 'indeed (the doctor) was little qualified for researches of the kind'. He has breakfast with 'a number of mad ladies and gentlemen, who by firmness, kindness, and routine, had been led into excellent habits; the linen was clean and the food good.' However, Alfred finds that this system is unfortunately accompanied by extra means to prevent escape, such as a higher number of attendants, and windows which do not open fully and have iron frames painted to look like wood.

\section{Was Hamlet mad?}

Alfred begins to realise that his attempts to get himself released might be long drawn-out and that he should perhaps both show less rage and also occupy himself by studying for his degree. Strategically, he becomes Wycherley's pet patient and receives useful tutelage for his Oxford exams, but they quarrel over whether Hamlet was mad or not. Alfred realises that, ironically, he must give in to Wycherley's 'monomania' on the subject in order to gain recognition of his own sanity.

" "Doctor," said he, "I have been thinking over your arguments, and I capitulate. If Hamlet ever existed, he was as mad as a March hare." And he blushed at this.' And so Dr Wycherley becomes convinced that Alfred is of sound mind.

A review of Conolly's 1863 A Study of Hamlet can be read in this Journal's predecessor. Conolly did indeed hold that Hamlet had 'a temperament in which madness lies very near the surface, and which some violent shock . . . is certain to develop into disease', and that he was not feigning, but manifesting, madness. Maudsley remarks in his obituary that Conolly's essay, while elegant, reveals 'the extent of his insight and the depth of his philosophy'. However, Maudsley has just characteristically commented that 'the philosophical depths of mental phenomena he never cared to sound', thus clarifying his view. 